\title{
Características da gordura cavitária da pirapitinga, Colossoma bidens, e do pacu-caranha, Colossoma mitrei (")
}

\author{
Francisco Pereira Castelo (**)
}

\begin{abstract}
Resumo
Neste trabalho, apresentam.se resultados de determinaçōes efetuadas em gordura cavitária da pirapitinga, Colossoma bidens (Spix, 1829) e do pacu-caranha, Colossoma mitrei. A gordura pertencente à primeira espécie foi proveniente do lago do Janauacá-AM, e a segunda espécie foi procedente da região do Jupiá, Estado de Mato Grosso. Ambas as espécies são peixes de água doce. A composição dos ácidos graxos foi determinada por cromatografia de gás e os componentes mais importantes, em ordem decrescente para ambas as espécies, foram: os ácidos graxos oleico, palmítico e esteárico. Fez-se desodorização da gordura sob vácuo, à temperatura de $160^{\circ} \mathrm{C}$, por três horas. Comparou-se - grau de desodorização através do ácido 2-tiobarbitúrico (TBA) e concluiu-se ser possivel desodorizar essa gordura e utilizá-la no preparo de alimentos. Através do teste sensorial com provadores, fritaram-se ovos na gordura de pirapitinga desodorizada, comparando-se os mesmos com ovos fritos em gcrdura de porco. Embora o resultado tenha colocado a gordura de peixe em posiçăo inferior, permaneceu na mesma classe "regularmente agradável", tendo os degustadores consumido a amostra total que lhes foi servida. No teste "vida de prateleira", a amostra armazenada sob vácuo à temperatura ambiente, após 3 meses, apresentou reversão de parte dos odores.
\end{abstract}

\section{INTRODUÇÃo}

O gênero Colossoma apresenta espécies de grande porte e elevado valor econômico. Existem duas espécies pertencentes a este gênero que são comercializadas com grande aceitação no Estado do Amazonas. O tambaqui, Colossoma macropomum (Cuvier, 1818), que é a espécie de maior produção, maior procura e maior valor econômico (Quadro 1), e a pirapitinga, Colossoma bidens (Spix, 1829) que tam. bém apresenta boa aceitação para o consumo direto, apenas como peixe resfriado (conservado em gelo). Já para o Estado de Mato Gros- so o pacu-caranha, Colossoma mitrei, é a espécie mais procurada para o consumo direto e para exportação interestadual, principalmiente para o Estado de São Paulo.

Estas espécies de água doce têm hábito alimentar muito variado, podendo ser classificadas como onívoras. Em vista disso sua importância cresce em relação ao seu aproveitamento para piscicultura.

A característica mais peculiar a estas espécies que nos motivou a elaboração deste trabalho, foi o acúmulo de gordura que se encontra depositada na cavidade abdominal. Essa gordura apresenta variação sazonal de acordo com o tipo de alimento consumido e varia também a sua tonalidade de coloração, desde o amarelo forte, ao amarelo claro. Essa gordura poderá ser utilizada na cozinha, no preparo de alimentos Castelo \& Rodriguez (1979). Quando usada para fritura, sem nenhum processamento tecnológico, elazimprime alguns odores desagradáveis em alguns tipos de alimentos, mas quando bem desodorizada, poderá ter utilização bastante ampliada, sem prodủzir nos produtos, odor de peixe

A juízo do DIPOA (1976), Art. 270, a comercialização usual de pescado no Brasil é realizada com exemplares eviscerados, quando sé trata de espécies de grande porte. Esse artigo poderá favorecer a obtenção de gordura cavitária dessas espécies com custo bastante reduzido, sem contudo inutilizar o pescado para qualquer processamento tecnológico a posteriori; daí, a viabilidade de aproveitamento dessa gordura.

O óleo de pescado de água salgada, para utilização na alimentação humana, é assunto

(*) - Apresentado ao II Congresso Brasileiro de Ciência e Tecnología de Alimentos, realizado em Joāo Pessoa.PB, de 19 a 22 de julho de 1978.

("*) - Instituto Nacional de Pesquisas da Amazônia/SUDEPE, Manaus. 
QUADRO 1 - Principais espécies de pescado desembarcadas em Manaus, em toneladas

\begin{tabular}{|c|c|c|c|c|c|c|c|c|c|}
\hline Espécie & 1970 & 1971 & 1972 & 1973 & 1974 & 1975 & $1976^{\star}$ & 1977 & 1978 \\
\hline Tambaqui & 3.918 & 4.739 & 4.473 & 3.077 & 5.522 & 12.742 & 13.607 & 9.692 & 6.547 \\
\hline Jaraqui & 2.589 & 1.712 & 2.590 & 3.089 & 3.662 & 5.012 & 4.925 & 6.468 & 7.960 \\
\hline Curimatã & 2.111 & 901 & 967 & 927 & 1.589 & 3.075 & 3.444 & 3.947 & 1.648 \\
\hline Pacu & 518 & 1.246 & 996 & 357 & 901 & 1.790 & 1.624 & 999 & 1.714 \\
\hline Tucunaré & 344 & 257 & 325 & 286 & 489 & 1.893 & 914 & 661 & 886 \\
\hline Pirapitinga & 332 & 179 & 68 & 293 & 475 & 784 & 1.510 & 955 & 473 \\
\hline Sardinha & 206 & 381 & 289 & 144 & 433 & 1.069 & 704 & 420 & 864 \\
\hline Matrinchä & 238 & 239 & 65 & 571 & 546 & 1.927 & 1.047 & 498 & 347 \\
\hline Pirarucu fresco & 147 & 62 & 28 & 91 & 135 & 566 & 168 & 42 & 94 \\
\hline Pescada & 75 & 107 & 177 & 101 & 133 & 662 & 274 & 191 & 272 \\
\hline Acará & 26 & 42 & 32 & 45 & 100 & 289 & 159 & 159 & 126 \\
\hline Branquinha & 63 & 134 & 211 & 242 & 199 & 237 & 539 & 139 & 258 \\
\hline Aracu & .. & 50 & 381 & 60 & 156 & 525 & 632 & 368 & 578 \\
\hline P. diversos & 292 & 1.081 & 542 & 255 & 406 & 1.260 & 1.238 & 622 & 861 \\
\hline TOTAL & 10.859 & 11.130 & 11.144 & 9.538 & 14.756 & 31.831 & 30.830 & 25.161 & 22.628 \\
\hline
\end{tabular}

(*) - Setor de Estatistica da Div. Peixe/Pesca - INPA'

FONTE - Colônia de Pescadores Z-2 de Manaus - AM.

muito controvertido. Atualmente, poucos são os países que fazem essa utilização (Contreras \& Neves Filho, 1974 e Stansby, 1967).

A literatura científica que trata deste assunto é escassa, mas é relativamente rica quando se refere à caracterização da composição desse tipo de produto. No entanto, pou$\cos$ estudos são realizados atualmente com óleo de peixe de água doce e não encontramos nenhum trabalho que fizesse menção ao aproveitamento da gordura cavitária de peixes, até a elaboração de nosso trabalho de tese, com a gordura cavitária do tambaqui (Castelo \& Rodriguez, 1979).

O óleo de pescado é normalmente um subproduto resultante da fabricação da farinha de peixe; desse modo, o preço tende a ser mais barato que o dos óleos obtidos das sementes vegetais. Por outro lado, o óleo de pescado está sujeito à sazonalidade das espécies que variam em qualidade e quantidade, durante $o$ ano, permitindo desse modo, fazer a opção (óleos vegetais), mesmo sendo mais cara, porém com a facilidade de dispor de oferta mais regular, dada a possibilidade de poder fazer-se estoques para trabalhar $o$ ano inteiro.
Um grande desvantagem que apresentam os óleos de pescado de água salgada tendo em vista a conservação, está relacionada com sua composição em ácidos graxos; estes são altamente insaturados com 3, 4, 5 e 6 duplas ligações, tornando-os bastante acessíveis ao oxigênio atmosférico, que pode causar-lhes oxidação e, conseqüentemente, sabores e odores indesejáveis. Isto pode ocorrer quando os óleos são armazenados à temperatura ambiente, logo após o processamento, sem a devida embalagem hermética.

Afora os inconvenientes relatados, o óleo de pescado de água salgada necessita ser hidrogenado para aumentar sua estabilidade e ganhar maior período de conservação (vida de prateleira), para ser utilizado no preparo de alimentos. Por outro lado, isto lhes dificulta o emprego como produto técnico. A hidrogenação, por ser um processo reversível, cria também um impasse para conservação do ó'eo em embalagens abertas, dado o processo de reversão dos odores de peixe.

O processo de reversão dos odores de alguns óleos e gorduras comestíveis é apresentado como uma reação em cadeia, cujos com- 
ponentes aparecem, mais ou menos em seqüência: primeiro aparecem os odores de manteiga; depois, de feijão, feno ou grama, de tinta e finalmente de peixe (Sherppard et al., 1978 e Stuckey, 1969).

A gordura de peixe de água doce, especificamente das espécies que trabalhamos, apresentá uma grande vantagem em sua composição físico-química, porque difere dos óleos de peixe de água salgada, nas seguintes características: o ponto de fusão é relativamente a!to, conferindo à gordura excelente plasticidade; 0 indice de iodo foi surpreendentemente baixo; a composição dos ácidos graxos foi diferente da composição dos óleos de peixe de mar.

Tomando por base o comprimento de cadeia de carbono e as duplas ligaçōes, Stansby (1967) diz que os ácidos graxos C20:5 e C22:6 são próprios de óleos de peixes de água salgada.

O óleo de peixe que é comercializado para consumo humano, além da operação de hidrogenização, necessita ser misturado a óleo vegetal, usualmente óleo de soja, como ocorre no Peru onde é misturado na proporção de $50-70 \%$, com boa aceitação (Contreras \& Neves Filho, 1974).

No Estado do Amazonas, há citação da utilização da gordura do tambaqui para consumo humano datando de 1933 (Magalhães, 1933). Conforme ficou provado em nosso trabalho (Castelo \& Rodriguez, 1979) não existe diferença marcante entre a batatinha frita em óleo de soja e a frita em gordura de tambaqui desodorizada. Por outro lado, a composição dos ácidos graxos da gordura de tambaqui não apresenta diferenças significativas para os ácidos graxos da gordura de pirapitinga e do pacu-caranha.

O consumo de alimentos fritos na gordura desses peixes será uma opção válida para o Estado do Amazonas, tendo em vista a completa dependência na importância de óleos e gorduras de outros estados brasileiros e exterior (Quadro 2).

Por ser a produção de pirapitinga pouco significativa, seria o aproveitamento da gordu- ra cavitária anti-econômico, casc não se tra. tasse de subproduto de custo de produçăo bastante reduzido, além de evitar o descarte dessa gordura, que iria contribuir para mais uma fonte de poluição ambiental. Considerando estes fatos, foi sugerido o aproveitamento da gordura cavitária no preparo de alimentos para consumo humano.

QUADRO 2 - Óleos e gorduras desembarcados em Manaus, em toneladas

\begin{tabular}{lrr}
\hline Tipo & 1975 & 1976 \\
\hline Banha & 5,0 & 20,0 \\
Oleos vegetais & $6.140,0$ & $5.856,0$ \\
Oleos animais (N.E.) & 451,0 & 276,0 \\
Azeite de Oliveira & 163,0 & 120,0 \\
& & \\
\hline & & \\
TOTAL & $6.759,0$ & $6.272,0$
\end{tabular}

(*) - Nắo especificado.

FONTE - Coleta na A.P.N.

\section{MATERIAL E MÉTODOS}

\section{MATERIAL}

A matéria prima utilizada neste trabalho foi gordura de pirapitinga Colossoma bidens (Spix, 1829), (Fig. 1), proveniente do lago de Janauacá, Estado do Amazonas, coletada em outubro de 1977 e de pacu-caranha, Colossoma mitrei, proveniente da região de Jupiá, Estado de Mato Grosso, adquirido em casa especializada na cidade de Campinas, Estado de São Paulo, em setembro do mesmo ano.

\section{Preparo da amostra}

Dos peixes abertos em bandas, conforme a Fig. 2, foi retirada a gordura, a qual, levada ao laboratório, foi liquefeita e conservada em refrigerador doméstico até o início do trabaIho.

\section{Determinação de ácidos graxos}

Para a determinação dos ácidos graxos, as amostras foram metiladas e injetadas em cromatógrafo de gás, utilizando coluna poiar de polietileno glicol succinato (PEGS) $1 / 8$, $17 / 5 \mathrm{Cr}$. W. e $80 / 100$. 


\section{Determinação dos índices de qualidade}

$\mathrm{Na}$ determinação dos índices de qualidade, fez-se uso de refratômetro à temperatura de $40^{\circ} \mathrm{C}$, balança analítica picnômetro, tintômetro Lovibond e espectrofotômetro.

\section{Desodorização da gordura}

Para desodorizar a gordura da pirapitinga, improvisou-se um equipamento mostrado na Fig. 3.

\section{Teste sensorial}

Para que fosse provada a gordura da pirapitinga, fez-se uso do Laboratório de Análise Sensorial da Faculdade de Engenharia de Alimentos e Agrícola - FEAA da UNICAMP-SP, onde se realizou a prova de degustação com provadores, usando-se a ficha mostiada na Fig. 4

\section{MÉTODOS}

\section{Desodorização}

Os óleos vegetais encontrados no comércio são normalmente desodorizados. O proces- so de desodorização emp:"egado pela indústria é baseado na diferença de volatilidade dos compostos odoríficos e gustativos. Utilizou-se o mesmo princípio para desodorizar a gordura cavitária da pirapitinga. Empregou-se alta temperatura, vapor direto e vácuo.

A temperatura empregada foi de $160^{\circ} \mathrm{C}$ por três horas e o vapor foi gerado com o auxílio de um bico de Bunsen e o vácuo foi proveniente de uma trompa d'água com a água à temperatura ao redor de $25^{\circ} \mathrm{C}$.

\section{Determinação dos ácidos graxos}

As amostras foram metiladas, empregando-se os métodos de AOCS (1974), para identificar os ésteres metílicos, fez-se uso dos padrões da Applied Science Laboratories, bem como se comparau o tempo de retenção da amostra e injetou-se ácido graxo conhecido, para verificação do acréscimo do pico correspondente.

\section{Índice de qualidade}

Para avaliação da qualidade da gordura cavitária da pirapitinga fez-se as determinações dos índices de acidez, peróxido, refração,

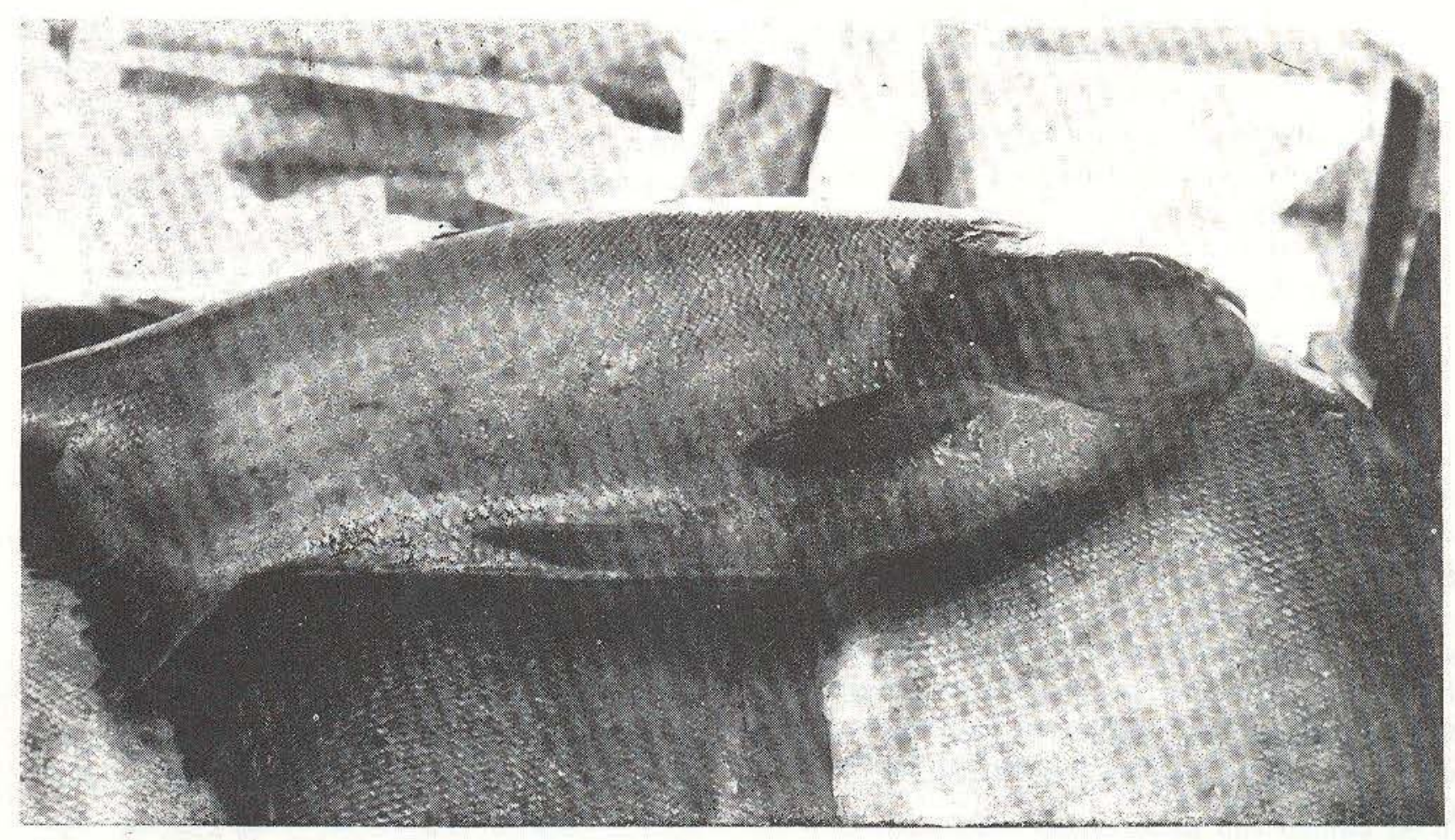

Fig. 1 - Vista latero-ventral de um exemplar de pirapitinga, pesando cerca de $10 \mathrm{~kg}$. 


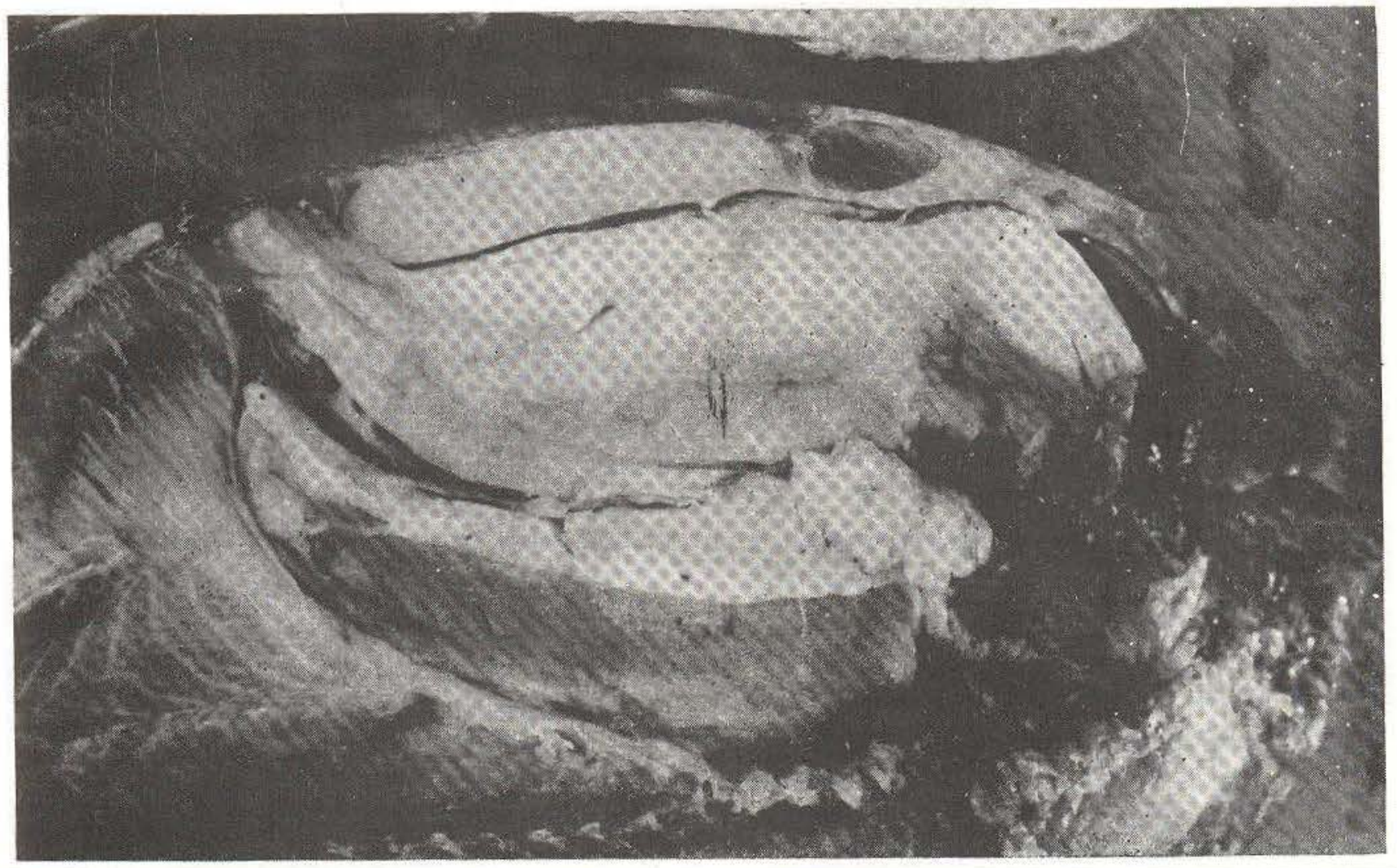

Fig. 2 - Banda de pirapitinga evidenciando a gordura cavitária.

saponificação, lodo, ácidos graxos livre, matéria insaponificável, cor, ponto de fusão( $\left.{ }^{*}\right)$, rancidez oxidativa, segundo YU \& Sinhuber ((1967), e ponto de fumaça, conforme descrito em Castelo \& Rodriguez (1979).

\section{Teste sensorial}

Apenas um teste sensorial foi realizado por provadores em cabines individuais, no laboratório de Análise Sensorial da Faculdade de Engenharia de Alimentos e Agrícola (FEAA), onde procurou-se estudar a viabilidade de aproveitamento da gordura de pirapitinga para fritura.

A equipe de 6 provadores foi servida ovo frito em gordura de pirapitinga desodorizada e compararam-se o sabor dos mesmos a ovos fritos em banha de porco comercial.
A distribuição das amostras foi em blocos ao acaso, e solicitou-se aos provadores a preferência quanto ao aroma, ao sabor e à acidez entre as amostras (Fig. 4).

\section{Resultados}

Os óleos e gorduras são as mais concentradas fontes de energia incluídas em nossa dieta, cerca de $9 \mathrm{kcal} / \mathrm{g}$. concorrem para essa forma de energia dos lipídeos, os triacilgliceróis com 92 a $97 \%$ da gordura total (Contreras \& Neves Filho, 1974). Os óleos e gorduras são constituídos de ácidos graxos, liberados através de hidrólise.

Os ácidos graxos da gordura cavitária das espécies que trabalhamos diferem dos ácidos graxos de peixe de água salgada e se assemelham muito à composição lipídica de ani-

(") Determinou-se o ponto de fusão através do aparelho Mettler "FP5", conforme a seguinte norma:

1. Com auxillo de uma espátula, espalhar pequena porção da amostra em uma lâmina de vidro comum, introduzi-la na câmara de aquecimento. Ligar o aparelho em velocidade que permita observar com precisão:

2. Verificar pela objetiva, quando se inicia a fusăo e registrar esse tempo inicial;

3. Continuar a observação em velocidade de aquecimento menor, até a completa fusăo da amostra total e desligar. 
mais, notadamente os ácidos graxos da gordura da galinha, conforme poderá ser comparado na literatura (Kursis, 1978).

Nas condições do presente trabalho a composição dos ácidos graxos das duas espécies apresentaram-se com bastante semelhança entre os seus constituintes. Tanto para a pirapitinga quanto para o pacu, os ácidos graxos foram: Oleico (C18:1), Palmítico (C16:0) e Esteárico (C18:0) em ordem crescente de quantidade (Quadro 3).

\section{Indices de qualidade}

Pelos resultados mostrados no Quadro 4, pode concluir-se que as amostras eram bastante heterogêneas.

\section{Desodorização}

Com base na diferença de volatilidade dos constituintes das substâncias odoríficas e gustativas dos óleos e gorduras, desodorizou-se a gordura cavitária da pirapitinga, durante 3 horas à temperatura de $160^{\circ} \mathrm{C}$ e vácuo de trompa d'água, estando a mesma com aproximadamente $25^{\circ} \mathrm{C}$.

QUADRO 3 - Composição percentual dos ácidos graxos da gordura cavitária da pirapitinga e do pacu-caranha

\begin{tabular}{|c|c|c|}
\hline Ácido graxo & Pirapitinga & Pacu caranha \\
\hline $\mathrm{C} 12: 0$ & 0,14 & 2.40 \\
\hline C14: 0 & 3.14 & 4,26 \\
\hline $\mathrm{C}_{14}: 1$ & 0,31 & 0,31 \\
\hline C15: 0 & 0,14 & 0,13 \\
\hline C16:0 & 27,00 & 22.00 \\
\hline C16: 1 & 9,80 & 6,64 \\
\hline C17: 0 & 0,20 & 0.22 \\
\hline C17: 1 & 0,13 & 0,00 \\
\hline C18: 0 & 11,00 & 8,78 \\
\hline $\mathrm{C} 18: 1$ & 43,48 & 4871 \\
\hline $\mathrm{C} 18: 2$ & 3,84 & 4,55 \\
\hline C18: 3 & 0,25 & 2,00 \\
\hline $\mathrm{C} 20: 0$ & 0,53 & 0,00 \\
\hline Saturados & 42,15 & 37,79 \\
\hline Monoinsaturados & 53,72 & 55,66 \\
\hline Polinsaturados & 4,13 & 6.55 \\
\hline
\end{tabular}

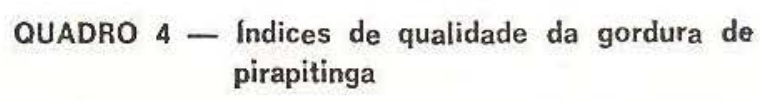
pirapitinga

\begin{tabular}{|c|c|c|c|}
\hline \multirow{2}{*}{$\begin{array}{l}\text { Determinações } \\
\% \text { de ácidos graxos livres }\end{array}$} & \multicolumn{2}{|c|}{ Valor } & limite \\
\hline & 0,16 & - & 2,00 \\
\hline Indice de acidez & 0,31 & - & 4,00 \\
\hline Indice de iodo & 79,00 & - & 86,00 \\
\hline Indice de peróxido & 1,36 & - & 10,00 \\
\hline Indice de refração & 1,4601 & - & 1,4603 \\
\hline Indice de saponificação & 195,00 & - & 210,00 \\
\hline Matéria insaponificável & 0,32 & - & 0,96 \\
\hline Ponto de fumaça & $173^{\circ} \mathrm{C}$ & & \\
\hline Ponto de fusão & 35,6 & - & $46^{\circ} \mathrm{C}$ \\
\hline \multicolumn{4}{|l|}{ Valor de TBA, mg de aldeido } \\
\hline malônico $/ 1000 \mathrm{~g}$ & 1,85 & - & 11,96 \\
\hline Cor (Lovibond) & $10 \mathrm{~A}$ & - & $3,5 \mathrm{~V}$ \\
\hline
\end{tabular}

Para avaliar-se o grau de desodorização obtido, fez-se o uso da determinação da rancidez oxidativa, através do ácido 2-tiobarbitúrico (TBA) de produtos comerciais e estabeleceu-se que abaixo da média do valor de TBA desses produtos, a gordura cavitária da pirapitinga estaria desodorizada.

Os resultados mostrados no Quadro 5, permite-nos concluir que a gordura da pirapitinga sofreu apenas uma leve desodorização, se considerarmos o pouco vácuo e a temperatura relativamente baixa para este tipo de operação.

É do conhecimento geral que, através da desodorização, se elimina primeiro os produtos odoríficos que são mais voláteis, seguindo-se-Ihes as substâncias gustativas. Isto ocorre durante os primeiros trinta minutos do processo e somente depois, começam a ser separados de óleo, os produtos oriundos da cisão dos glicerídeos (Meyer, 1968 e Rohr, 1974).

\section{Ácidos graxos livres (AGL)}

Os óleos de pescado, quando são destinados à comercialização, estão sujeitos às exigências impostas pelos compradores. Estes, usualmente, exigem as determinações de umidade, cor, percentagem de ácidos graxos livres, impurezas não lipídicas e poucos são aqueles que solicitam também índice de lodo e matéria insaponificável (Contreras \& Neves Filho, 1974). 


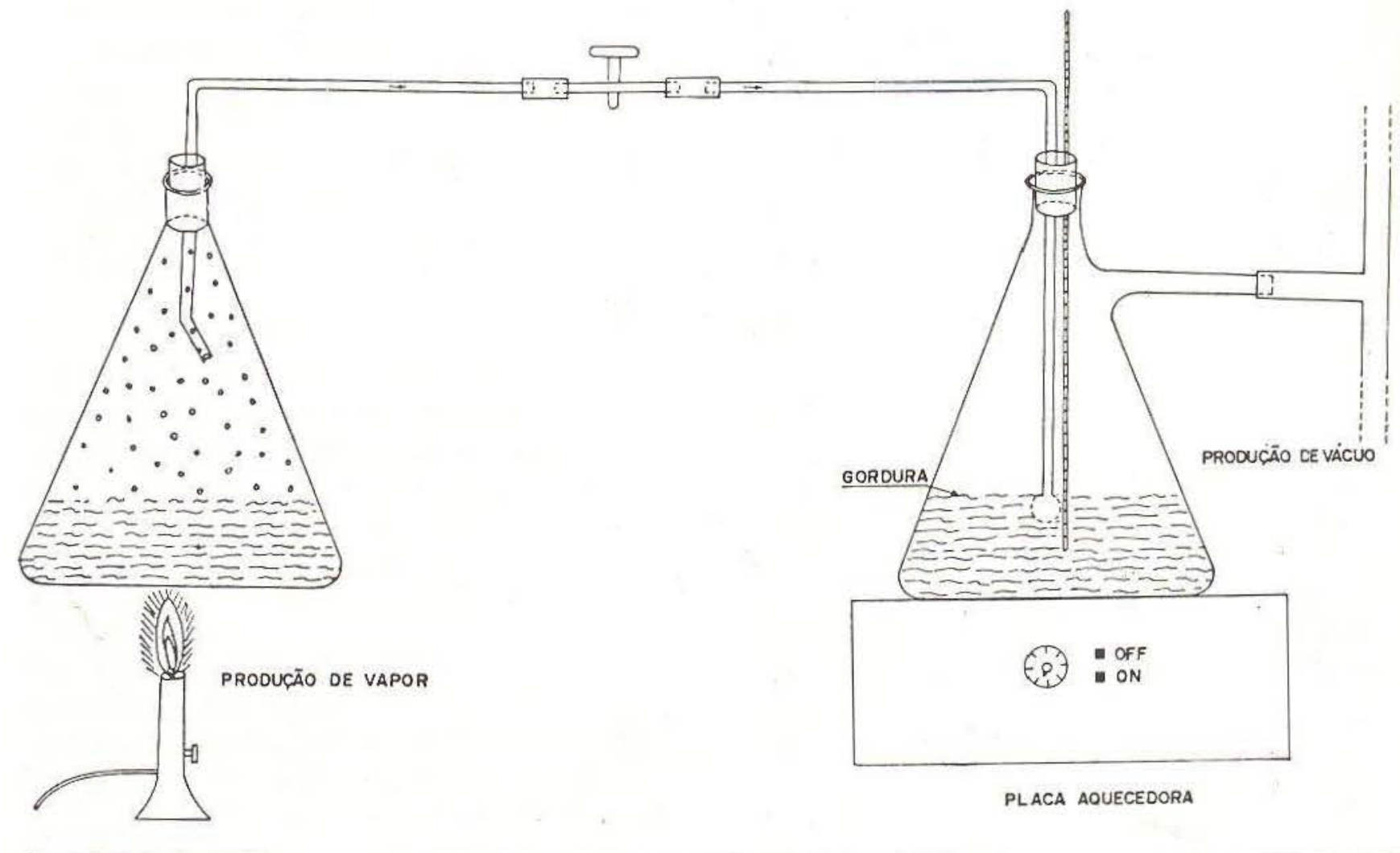

Fig. 3 - Esquema do aparelho de desodorização.

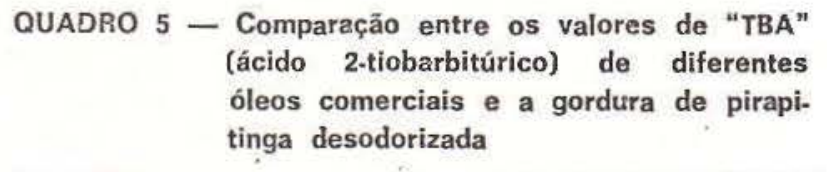

\begin{tabular}{cc}
\hline Tipo de óleo & Valor de TBA* \\
\hline A & 1,52 \\
B & 7,65 \\
C & 3,81 \\
D & 3,84 \\
\hline Média & 4,20 \\
\hline Gordura de pirapitinga & 3,55 \\
\hline (*) - TBA $=$ mg de aldeido malónico por $1000 \mathrm{~g} \mathrm{de}$ \\
amostra.
\end{tabular}

Os AGL encontram-se nos óleos de peixe de água salgada em proporção relativamente alta, dependendo do estado de conservação da matéria-prima do processamento da embalagem do produto final, podendo estas causas agirem isoladamente ou em conjunto.

Para acidez expressa como ácido graxo livre, é estabelecido freqüentemente o valor de $0,1 \%$ para óleos e gorduras comestíveis, embora não tenha fundamento sob o ponto de vista nutritivo nem degustativo (Hartman, 1971). Os ácidos graxos livres só influenciam o paladar dos alimentos quando provém de cadeia de carbono de número menor que 14 átomos. As cadeias compostas com ácido graxo, cujo número de carbono predominante for de 16 a 18 átomos na molécula, mesmo que apresentem até $3 \%$ de acidez em ácido oleico, não influenciam o sabor (Hoffeman et al., 1971).

\section{Indice de acidez}

A acidez dos óleos e gorduras é expressa normalmente como sendo ácido oleico e refere-se ao número de $\mathrm{mg}$ de $\mathrm{KOH}$ necessário para neutralizar os ácidos graxos livres de $1 \mathrm{~g}$ de amostra (AOCS, 1974).

A lei que regulamenta o comércio deste tipo de produto no Brasil consigna que a acidez dos óleos refinados deve ser equivalente ao teor de $1,5 \mathrm{~m} 1$ de $\mathrm{NaOH} 1 \mathrm{~N} / 100 \mathrm{~g}$ de óleo, o que corresponde a $0,42 \%$ de acidez, calculada como ácido oleico. 
Conforme pode verificar-se no Quadro 4, a gordura cavitária de pirapitinga apresentou acidez relativamente baixa, quando comparada aos óleos e gorduras comerciais

\section{Indice de lodo}

$O$ índice de lodo indica o grau de insaturação da gordura ou óleo expresso em gramas de lodo absorvido por $100 \mathrm{~g}$ de amostra, AOCS (1974). O índice de lodo de óleo de peixe de mar encontra-se em torno de 110 a 250 , sendo que os valores que excedem de 200 são derivados dos fosfolipídeos (Stansby, 1973).

O valor médio de 82 para o índice de lodo encontrado na gordura de pirapitinga mostra uma quantidade bastante alta de ácidos graxos saturados, o que ocasiona ao produto uma consistência pastosa em temperatura ambiente.

\section{Ponto de fusão}

O ponto de fusão da gordura cavitária foi relativamente alto (Quadro 4), o que ocasiona a diminuição da uttilização da gordura de pira- pitinga para elaboração de procututos comestíveis. Os óleos destinados ao aproveitamento em salada e maionese, deverão ter o ponto de fusão inferior a $4^{\circ} \mathrm{C}$, admitindo-se uma variação até $7^{\circ} \mathrm{C}$, enquanto que para os produtos destinados à fritura, este aspecto não deverá ser levado em consideração.

\section{Teste sensorial}

A melhor forma de conhecer-se objetivamente a qualidade de um produto acabado é através da análise sensorial empregando provadores treinados para emitir opiniōes com relação às vantagens ou desvantagens que o produto em teste possa apresentar, em relação a outro produto similar.

- No Quadro 6, verificaram-se os valores obtidos com seis provadores que degustaram ovo com pão "tipo francês", frito em banha de pirapitinga "desdorizada" e compararam com ovos fritos em banha de porco.

Embora os resultados do Quadro 6 não possam ser considerados estatisticamente vá-

NOME: DATA:

PRODUTO: SÉRIE:

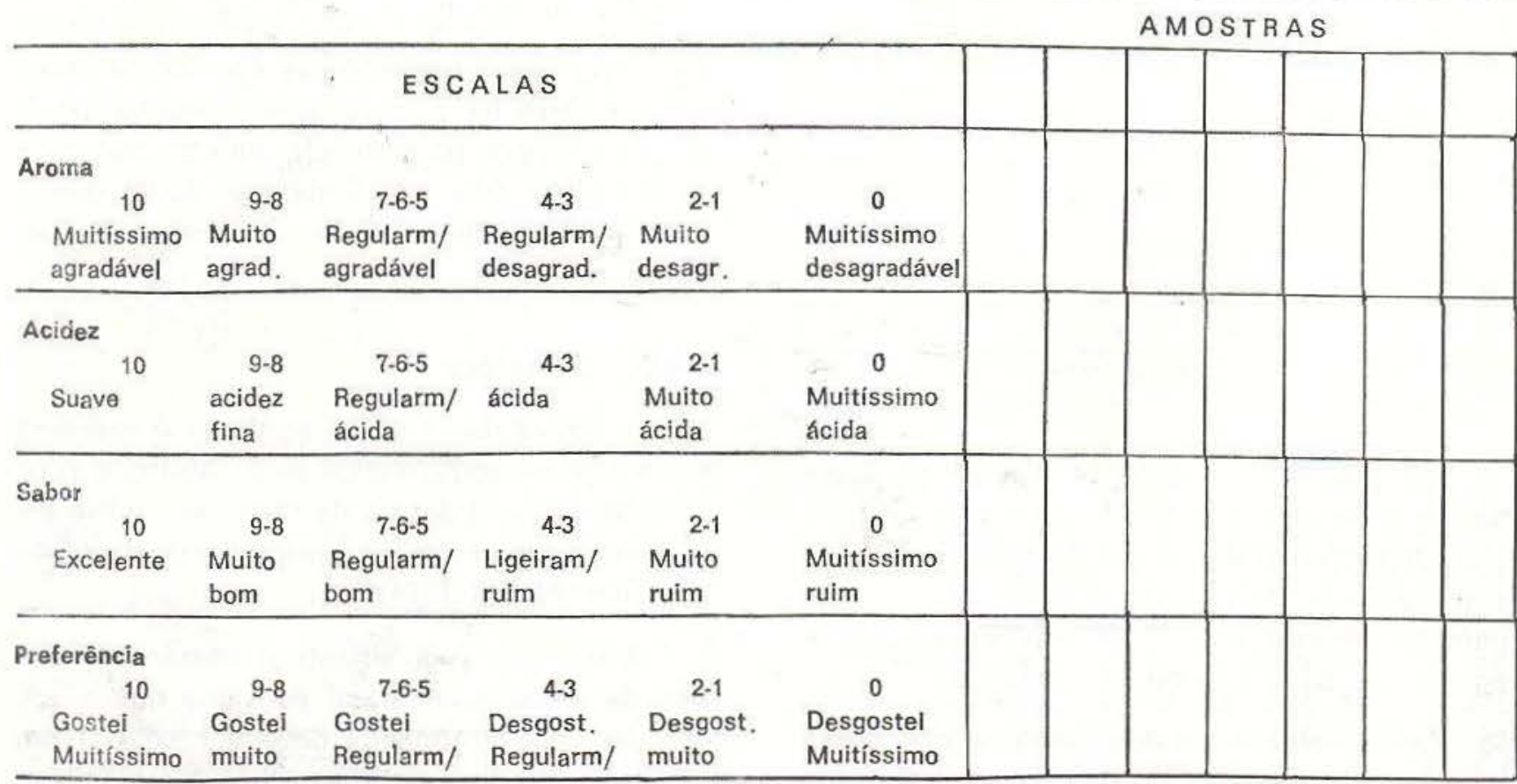

Comentários:

Fig. 4 - Ficha apresentada à equipe de provadores na análise sensorial. 
lidos, mesmo assim, aconselhamos o aprovei. tamento da gordura cavitária para consumo humano, com base no fato de os provadores não terem rejeitado a amostra; muito pelo contrário, todos eles consumiram a amostra total que thes foi servida.

QUADRO 6 - Resultado do teste sensorial com gordura de pirapitinga e banha de porco usando seis provadores

\begin{tabular}{l|c|c}
\hline Discriminaçäo & $\begin{array}{c}\text { barhha de pira- } \\
\text { pitinga }\end{array}$ & $\begin{array}{c}\text { banha de porco } \\
\text { (padrão) }\end{array}$ \\
\hline Aroma & 39 & 48 \\
Acidez & 46 & 51 \\
Sabor & 41 & 48 \\
Preferência & 41 & 48 \\
\hline & 167 & 195 \\
\hline
\end{tabular}

\section{Discussão}

A maioria das publicaçōes que tratam da desodorização de óleos e gorduras é unânime em afirmar que a quase totalidade dos produtos odoríficos e gustativos são eliminados nos primeiros trinta minutos do processo de desodorização (Rohr, 1974). Mesmo assim, supôsse que a gordura de pirapitinga não tenha sido totalmente desodorizada, tendo em vista o pouco vácuo utilizado, assim como a reversão dos odores ocorrer em pouco mais de 90 dias de estocagem, causando um aumento no valor de TBA de 1,85 para $11,96 \mathrm{mg}$ de aldeido malônico por $1000 \mathrm{~g}$ de amostra. Contudo, batata, frita nessa gordura não apresentou gosto de peixe, nem odor nauseante.

É necessário salientar que sejam consideradas as deficiências apresentadas pelo aparelho de desodorização, que, certamente, seriam sanadas com a utilização de equipamento adequado.

Conforme se verifica no Quadro 1, a produção de pirapitinga desembarcada em Manaus nos últimos anos foi bastante irregular; mesmo assim, quase sempre está colocada entre as cinco primeiras espécies comerciali- zadas. Isso mostra a boa aceitação e a impor. tância dessa espécie para o desenvolvimento regional.

Com o trabalho pioneiro da criação em viveiro da pirapitinga realizado por Silva et al. (1973), no qual obtiveram desova induzida da pirapitinga por aplicação intramuscular de extrato hipofisário de espécie heteróloga e também, mais recentemente Almeida et al. (1977), conseguiram a desova em cativeiro de pacucaranha, através de aplicação de gonadatrofina cariônica proveniente de placenta humana. Por estes motivos é que vem crescendo de importância econômica a utilização dessas espécies para a piscicultura intensiva. Dadas estas evidências, o aproveitamento da gordura cavitária dessas espécies para a alimentação humana, será mais uma alternativa lógica, como conseqüência da utilização dessas espécies para a piscicultura.

Embora o peso médio da pirapitinga seja estimado em $3,5 \mathrm{~kg}$, já foi encontrado exemplar no mercado municipal de Manaus, pesando $11,2 \mathrm{~kg}$, com $790 \mathrm{~mm}$ de comprimento total (Silva et al., 1973).

Observando a composição dos ácidos graxos (Quadro 3) da gordura cavitária da pirapitinga e do pacu-caranha, concluiu-se que as duas gorduras são semelhantes. As poucas diferenças existentes estão relacionadas com a presença do ácido graxo monienóico (C17:1) e eicosaenóico (C20:0) encontrados nessas gorduras. Apesar dessa diferença em ácido graxo insaturado a favor da gordura da pirapitinga, o pacu-caranha ainda apresentou maior proporção, tanto de monoinsaturados quanto de polinsaturados.

Não obstante os resultados do Quadro 3 , não indicarem presença dos ácidos graxos $\mathrm{C}_{8}$ e $\mathrm{C}_{10}$, por terem sido encontrados em quantidades muito pequenas, foi quase constante a eluição dos referidos ácidos.

Como não se fez uso de coluna tipo PEGS, elimina-se a possibilidade de esses picos terem sido originados pela oxidação dos ésteres metílicos no interior da coluna. Por outro lado, levando-se em conta que a metilação me- 
tanólica pelo trifluoreto de Boro (reagente $\mathrm{BF}_{3}$ ) empregada por nós, é considerada mais hábil para detectar estes tipos de ácidos graxos, (Kursis, 1978), o que justifica o aparecimento desses ácidos graxós na composição dessas gorduras.

Considera-se a origem dos ácidos graxos como proveniente da dieta alimentar e, como essas espécies são consideradas onivoras, isto é, alimentam-se de grandes quantidades de frutos e vegetais diversos, como ocorre com o tambaqui (Castelo \& Rodriguez, 1979), pode explicar-se a semelhança apresentada por essas gorduras mais a óleos e gorduras vegetais, do que propriamente a óleo de peixe de mar.

Essas gorduras apresentam razoável labilidade à alta temperatura, tendo em vista as alterações causadas aos micro-constituintes, como, por exemplo, a destruição dos antioxidantes naturais e outros pigmentos responsáveis pela coloração amarela acentuada dessa gordura quando in natura.

Os resultados apresentados no Quadro 6 poderão ser considerados relevantes, porque, quando se comporam as qualidades de um produto com as de outro de uso corrente, o resultado tanto poderá ser favorável como desfavorável, ou ainda, como no presente caso, o produto pode ser aceito com diferença pouco significativa isto é, a média recebida pelo produto pode ser inferior à média do padrão considerado.

Isto nos parece lógico, quando se considera que a banha de porco já foi utilizada em fritura por longa tempo na cozinha brasileira, além de apresentar a peculiaridade de imprimir ao produto odores e sabores próprios, deixando-o com sabor bem mais apetecível.

\section{AGRADECIMENTOS}

O autor agradece o apoio recebido do pessoal dos Laboratórios de Análise Instrumental, Sensorial e Químico da FEAA - UNICAMP-SP, e do pessoal do Laboratório de Lipídios do ITAL. Estende também seus agradecimentos ao Depto. Peixe/Pesca, pela remessa de material, e o apoio financeiro do CNPq e SUDEPE, através do INPA.

\section{SUMmary}

This paper deals with "cavity fat" composition of Pirapitinga Colossoma bidens, (Spix 1829) and pacu-caranha Colossoma mitrei. Both species are fresh-water fishes. The Pirapitinga fat was obteined from Janauacá Lake, Amazonas, and the pacu-caranha's from Jupiá Region, Mato Grosso. The fatty acids composition was determined by gas chromatography and the most Important constituents were: oleic, palmitic and stearic fatty acids. The fat was deodorized on vacuum, at $160^{\circ} \mathrm{C}$ for three hours. Degree of deodorization comparision utilizing 2-thiobarbituric acid (TBA), led to the conclusion that it is possible to deodorize this fat and utilize it in food preparation. The deodorized pirapitinga fat was subjected to sensorial tests by tasters. For this purpose, eggs were fried in deodorized pirapitinga fat and in pork fat, and thereupon compared. Although results place the fish fat on an inferior position, it remained however in the same class, namely, "regularmente agradável". In shelf life tests, samples were stored on vacuum at room temperature. After three months, there occured partial reversion of the odors.

\section{REFERENCIAS BIBLIOGRAFICAS}

AOCS - American Oil Chemist's Society.

1974 - Official and tentative methods of the A.o.C.S. 3 ed. Chicago, : 25, 40, 45, 53 . $62,63,66$.

ALMEIDA, P.I.R. et al.

1977 - O Instituto de Pesca consegue fecundaçăo de pacu em aquário. Rev. Nacional da Pesca, (162).

CONTRERAS, E.S.G. \& NEVES FILHO, L.C.

1974 - Emprego industrial do óleo de pescado. Rev. Nacional da Pesca, (138).

CASTELO, F.P. \& RODRIGUEZ, D.A.

1979 - Aproveitamento e características da gordura cavitária do tambaqui, Colosso. ma macropomum, Cuvier (1818), FEAA. UNICAMP-SP. Tese, $90 \mathrm{pp}$.

DIPOA - Departamento de Inspeção de Produtos de Origem Animal.

1976 - Regulamento de Inspeção Industrial e Sanitária de Produtos de Origem Animal. M.A., Lei 1.283 de 18 de dezembro de 1950, Dec. n.० 30.691 de 29 de março de 1952. Brasília-DF. 
HATMAN, Leopold \& TOSELLO, André.

1971 - Desacidificação de óleos comestiveis sem emprego de alcalis. FEAA-UNICAMP. Tese.

HOFFEMANN, G. et al.

1971 - Lipids and their oxidation. In: ANTUNES, A.J. Efeitos dos ácidos graxos livres sobre a estabilidade... FEAA-UNICAMP-SP. Tese.

KURSIS, A.

1978 - Fatty acid composition of glicerolipids of animal tissues. In: Handbook of lipid research. New York, Plenum Press, (8) 383.

MAGALHÃES, A.C.

1933 - Monographia brasileira de peixes fluviais. Graphicars, p. 168/170.

MEYER, L.H.

1968 - Fats and other lipids. Food Chemistry. Reinhold Book Corporation. New YorkLondon, p. 40 .

ROHR, R.

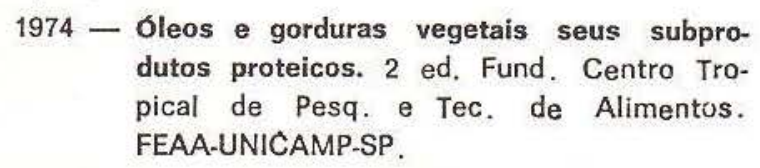

SHERPPARD, A.J. et al.

1978 - Composition of selected dietary. Fats, oils, margarines, end batter. In: Handbook of lipid research. Arms Kursis Ed. Plenum Press, New York and London, (8) : 341/375.

SILVA, A.B. et al.

1973 - Observações preliminares em viveiro com pirapitinga Colossoma bidens, (3) parte II. DNOCS (Série Estudos de Pesca).

STANSBY, M.E.

1967 - Fish oils. New York - London. The AVI Pub. Co. Inc.

1973 - Problems discouraging use of fish oil in American. Manufactured shortening and margarine. J.A.O.C.S. 50(6): 22)A-225A

STUCKEY, Ben N.

1969 - Antioxidants as food stabilizars. Handbook of food additives. Furia, R.E. ed. The Chemical Rubber Co. Granwood Parkway. Cleveland. Ohio, (5) : 217.

YU, T.C. \& SINHUBER, R.O.

1967 - An improved 2-tiobarbituric acid (TBA) procedure for the measurement of autoxidation in fish oils, J.A.O.C.S. (44):256-258.

(Aceito para publicação em 15/09/80) 